\title{
Matrix Acidizing Of Yamama Pay Zones
}

\section{Prof. Dr Ali M. Al-mashat - Prime Minister Office, Advisory Commission Dr. Kareem A. Alwan - Expert -Ministry of Oil - PRDC}

\section{$\underline{\text { Abstract }}$ \\ $Y_{\text {amama }}$ formation in} southern of Iraq has been studied well, and 25 core samples have been chosen from 7 wells to study their responses to matrix acidizing experiments by different acid solutions. It is found that:

1. Solutions of $5 \% \quad \mathrm{HCl}$ as preflushes and afterflushes are needed in volume depended on cores porosity.

2. A solution of $15 \% \mathrm{HCl}$ with its additives $[0.6 \% \quad \mathrm{~A}-250$ and $0.75 \%$ of the solution of Iraqi detergent powder] was the suitable solution for the stimulation of these cores.
Previous acid treatments were analyzed and the following techniques were suggested to get the best results:

1. Using paccaloni planningevaluation method to get the best quality control.

2. Placing the acid in front - of the perforation interval.

3. After completion of acid injection, an immediate opening to flow is necessary.

4. Adequate cleaning period would be important after acid job.

\section{$\underline{\text { Introduction }}$}

Any unintended impedance to the flow of fluids into or out of a wellbore is referred as formation damage. This broad 
definition of formation damage includes flow restrictions caused by a reduction in permeability in the near wellbore region, changes in relative to the hydrocarbon phase, and unintended flow restrictions in the completion itself ${ }^{(1)}$. Zone of reduced permeability between a formation and perforated casing was known "Skin" (2).

Skin factor "S" was defined quantitatively by everdengen ${ }^{(3)}$ as a constant which relates the pressure drop in the Skin to the dimensionless rate of flow:

$$
\Delta \mathrm{P}=\mathrm{S}\left(\frac{141.2 \mathrm{Q} \mu \mathrm{B}_{0}}{\mathrm{Kh}}\right)
$$

Skin factor, S, relates to altered zone radius (rs) and altered permeability (Ks) by the following equation ${ }^{(4,5)}$ :

$$
\mathrm{S}=\left(\frac{\mathrm{K}}{\mathrm{K}_{\mathrm{S}}}-1\right) \ln \left(\frac{\mathrm{r}_{\mathrm{s}}}{\mathrm{r}_{\mathrm{w}}}\right)
$$

This equation indicates that:

1. $\mathrm{S}$ will be negative when $\left(\mathrm{k}_{\mathrm{s}}\right)$ is greater than $(\mathrm{k})$, (stimulated zone).

2. $\mathrm{S}$ will be zero when $\left(\mathrm{k}_{\mathrm{s}}\right)$ is equal to $(\mathrm{k})$.

3. $\mathrm{S}$ will be positive when $\left(\mathrm{k}_{\mathrm{s}}\right)$ is less than (k), (damaged zone).

The purpose of any acid treatment is to dissolve rocks (or damaging materials), thus to enlarge existing channels and to open new paths to the well bore (6). In other words, stimulation means the reduction of skin factor value from $(+)$ ve one to zero or (-) ve value.

\section{Matrix Acidizing}

Matrix acidizing is the injection of acid into matrix structure of a formation at a pressure less than the hydraulic 
fracturing pressure of that formation $^{(6)}$, while acidizing treatments resulting by using injection pressures above fracture pressure are termed "fracture acidizing". A matrix treatment restores permeability by removing damage around well, thus improving productivity in both sandstone and carbonate wells.

The first acid treatment had been done by Herman Frash in $1895^{(7)}$, and from that date until (1960’s)

continuous

developments were took place in the matrix acidizing art (technique and additives ...).

Since late (1960's) the researches in matrix acidizing subject were concentrated into "quality control", or design and evaluation of the treatment to get the best results with minimum costs ${ }^{(8)}$.

Stimulation treatment were evaluated normally by the analysis of the bottom hole pressure tests before and after the treatment ${ }^{(5)}$.

McLeod et $\mathrm{al}^{(9)}$ and Paccaloni $^{(10)}$ developed new methods to evaluate the matrix acidizing during execution using the well head injection pressure.

Dowell $^{(11)}$ developed a modern method to evaluate the matrix acidizing using a computer system in the field.

The well designed treatment job is that job with the minimum acid volume and the minimum number of additives which gives the maximum productivity improvement ${ }^{(8)}$.

Theoretical work had been done to predict the distance from well bore the acid effect will reach $i t^{(12,13)}$, and several attempts and models have been made to quantify and thus to predict reaction patterns ${ }^{(14)}$. But neither theoretical nor experimental studies can predict exactly the number, size, or length of wormholes. Few 
methods can approximate the wormhole length.

Previous studies on the $\underline{\text { stimulation of Iraqi Oil fields }}$

Morrica (1981) studied experimentally the stimulation of Mishrif formation in halfaya fields using small core samples (15).

$\mathrm{He}$ found that the $\mathrm{HCl}$ acid $28 \%$ with fluid loss additives was needed for vuggy core samples, and $28 \% \mathrm{HCl}$ (retarded) was needed for chalky core samples.

Agip (1986) studied the stimulation of oil wells and water injection wells in Mishrif formation in west Qurna field (16). Small core samples $(1 * 1.5$ inches) were used. As a conclusion, they suggested to stimulate the lower permeable zone (MA) first and then stimulate the both zones (MA and $\mathrm{MB}$ - the high permeable one) ${ }^{(17)}$.
Abdel Amer, M. R. (1987) and Al-Taii (1988) carried out laboratory experiments to investigate the effect of different-concentrations of acid and certain additives on matrix acidizing of Mishrif formation core samples ${ }^{(18,19)}$. The optimum acid and additives conceutration had been found which gave the best responses and acceptable corrosion rate of steel.

\section{Yamama formation}

This formation was found in most oil fields in the south of Iraq with very important oil pay zones $^{(20)}$.

It represents very complex sequence of carbonate rocks which differ horizontally (from field to field) according to the depositional environments (as shown in fig.1), and vertically because it deposited in six swallowing upward cycles ${ }^{(21)}$.

These cycles produced six carbonate-grains units (A1, A2, 
$\mathrm{B} 1, \mathrm{~B} 2, \mathrm{~B} 3$, and C) isolated by basional or lagonal mudstone (21)

Many difficulties were
reported in stimulation of
Yamama formation some of
these are ${ }^{(20)}$ :

1. Impossibility of acid injection (sometimes) even when high injection pressure was used.

2. The failure to predict the success of acid job.

In 22 Oil wells, 103 acid jobs have been done, from these only 66 jobs were successful and 37 jobs were not ${ }^{(20)}$.

This high percent of failure made the study of the stimulation of oil well in thus formation is necessary.

\section{$\underline{\text { Stimulation of Yamama pay }}$}

$\underline{\text { zones }}$

Laboratory analysis of the petrophysical properties of Yamama formation cores from wells A (3186-3372) m, B (3587-3737) $\mathrm{m}$, and G (44104599) $\mathrm{m}^{(20)}$ were represented as a survey of $\log$ permeability (md) and porosity (fraction) vs depth (figers 2,3, and 4 respectively). From these figures it is found that there is a proportional relation between porosity $\phi$ and permeability $\mathrm{K}$ values. 


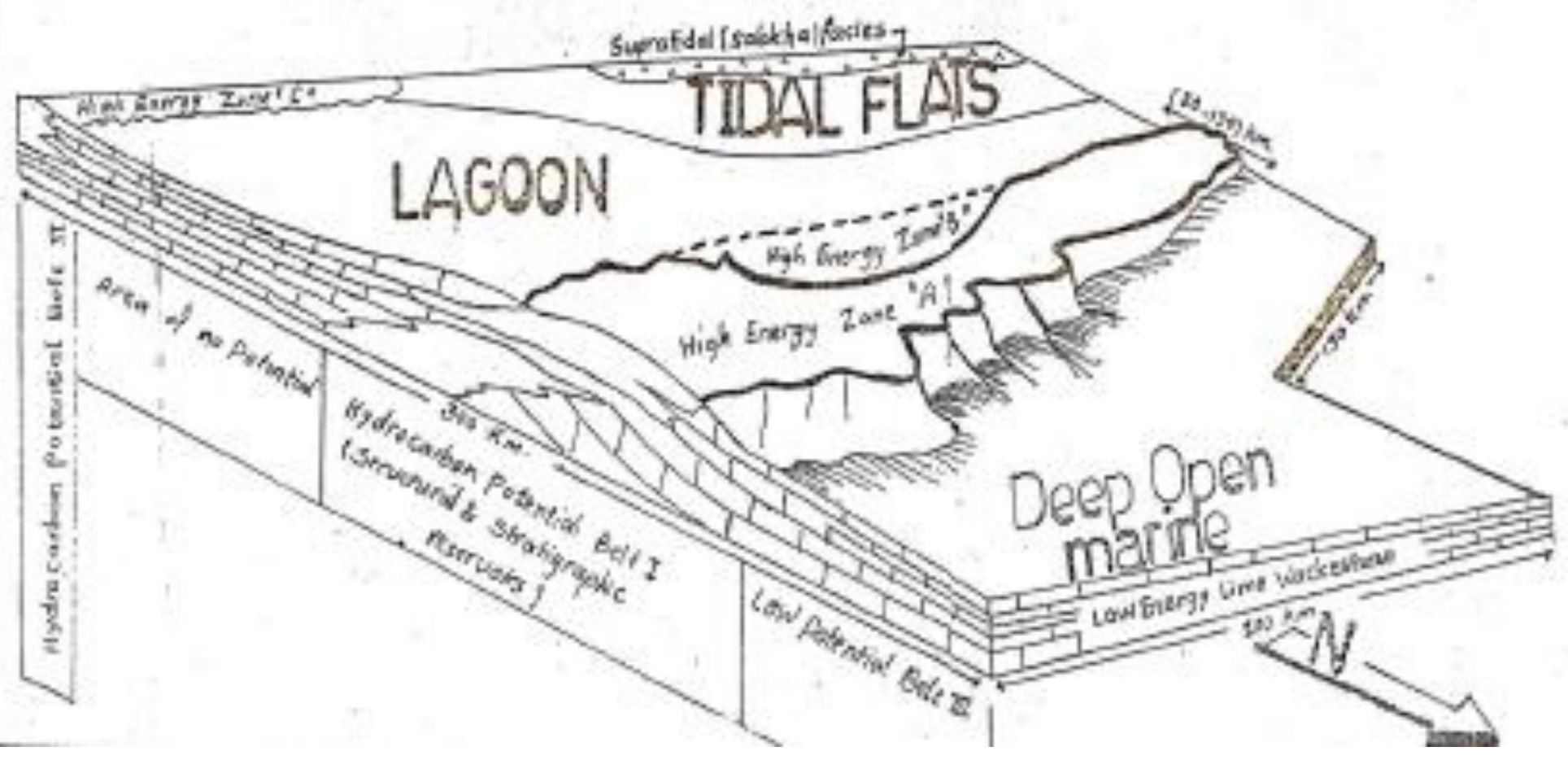

\section{Stimulation of Yamama pay zones}

Laboratory analysis of the

petrophsical properties of

Yamama formation cores from wells A (3186-3372) m, B (3587-3737) m, and G (44104599) $\mathrm{m}^{(20)}$ were represented as a survey of log permeability (md) and porosity (fraction) vs depth (fig.2,3, and 4 respectively). From these figures it is found that there is a proportional relation between porosity $\phi$ and permeability $\mathrm{K}$ values. 


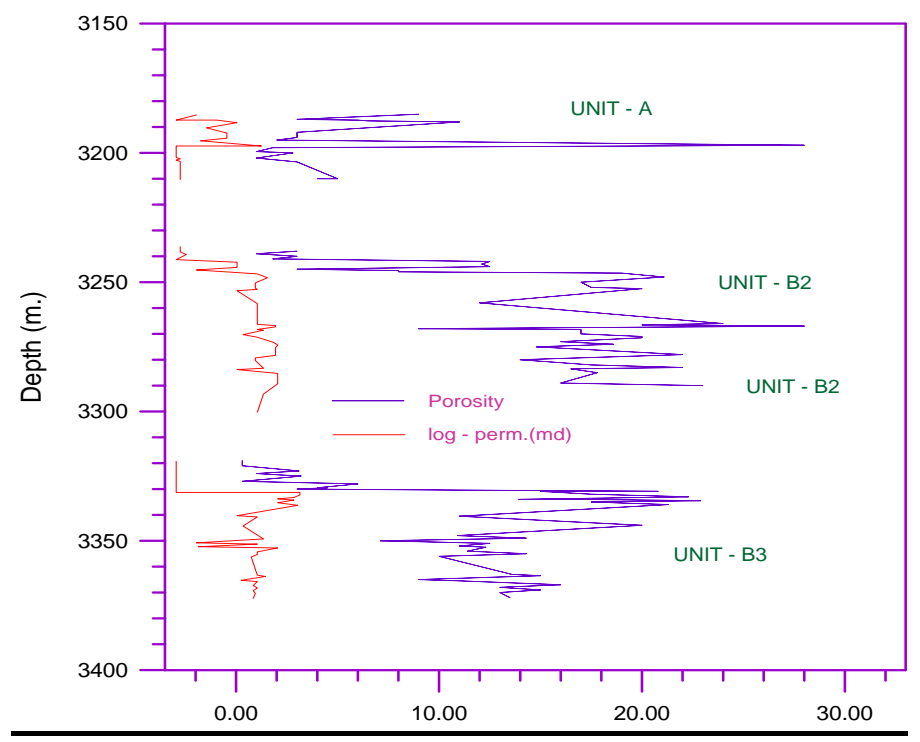

fig (2): petrophysical survey of well (A)

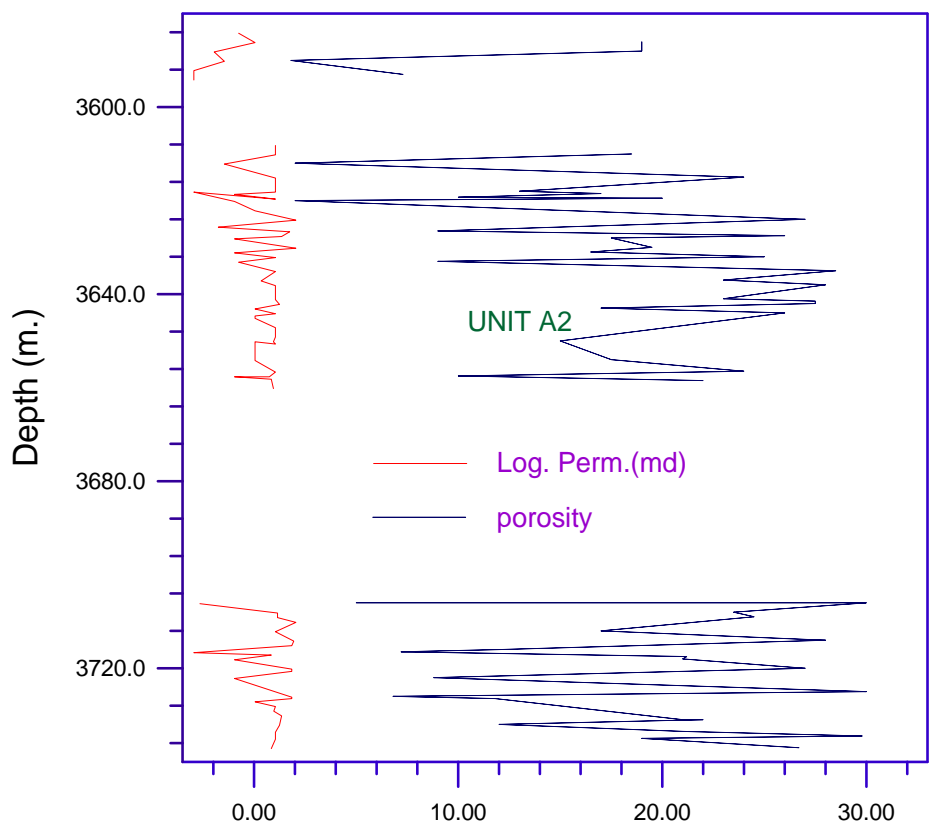

fig (3): petrophysical survey of well (B) 


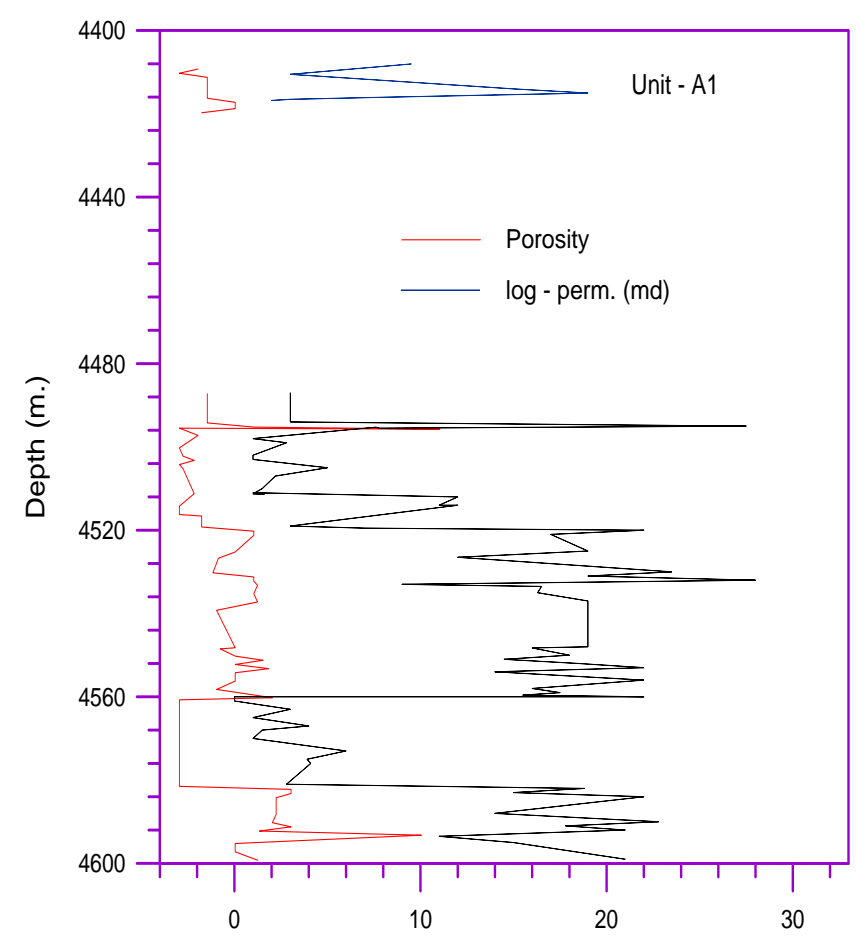

fig (4): petrophysical survey of well (G)

Fig.5 shows a statisticalgeometrical relation between $\phi$ and $\mathrm{K}$ values of these cores after dividing them into four groups according to their porosity values.

It is clear that:

1. Group $1(\phi<10 \%)$ is impermeable.

2. Group $2(10 \% \leq \phi<15 \%)$ is low permeability.

3. Groups 3 and $4(15 \% \leq \phi$ $<20 \%)$, and $(\phi \geq 20 \%)$ are medium to high permeability.
This conclusion leads to the possibility of using the porosity values (which can be measured easily) in any interval as an indicator to the permeability of this interval, and thus the treating conditions of it since several reports indicated that the amount of argillaceous materials present in the matrix structure of Yamama cores reversely proportion with porosity and permeability values $^{(20)}$. 


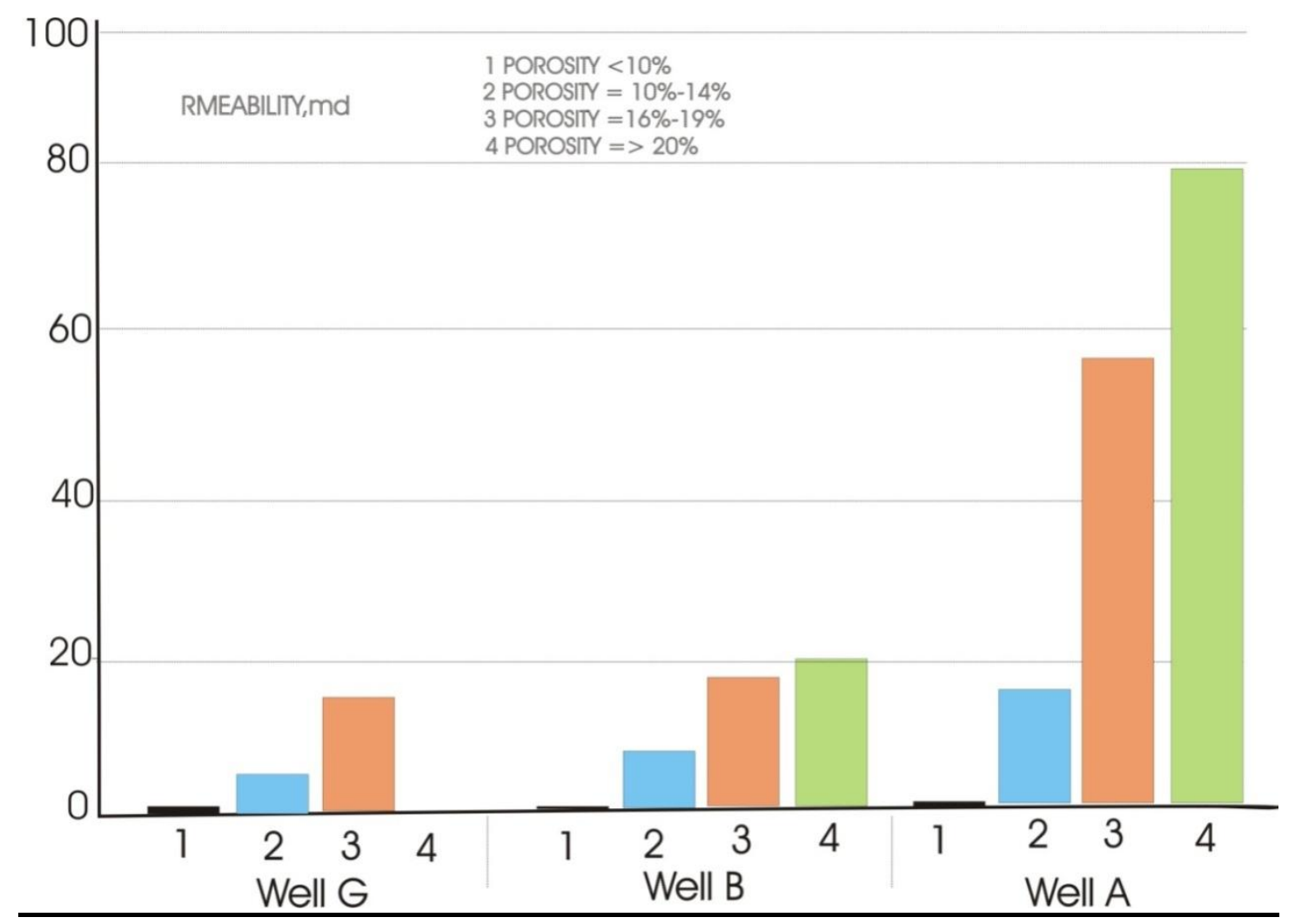

Fig (5): statistical geometrical relations

Well a, total No of samples $=149$, Report No: $\operatorname{soc} 742$

Well B, total No of samples $=143$, Report No: soc 801

Well C, total No of samples $=76$, Report No: soc 947

\section{$\underline{\text { Experimental work }}$}

Twenty one medium core

samples (1.5 x 4.0 inches) and 4 small core samples $(1.0 \times 1.5$ inches) had been taken from 7 wells in different fields, small samples had been pulverized.
Crude oil and formation water had been taken from NS field and WQ field.

N-80 steel coupons, three types of acid corrosion inhibitors, and two types of non - emulsifying agents were used. 
The following experiments had been done:-

1. Acid corrosion tests.

2. Acid emulsion tests.

3. Sludge tests.

4. Visual wettability tests.

5. Solubility tests.

6. Measurements of spending times.

7. Acid flow tests (matrix acidizing treatments).

Fig (6) shows the diagram of the matrix acidizing apparatus which was used in acid flow tests mentioned in item 7.

\section{Anew equation to determine}

\section{wormhole lengths}

$\mathrm{F}_{\text {rom acid flow tests some of }}$ cores were completely penetrated by acid wormholes under the conditions of experiments and during certain times. From these results an empirical equation was developed to determine the length of wormhole which will be created in Yamama rocks during matrix acidizing treatment, therefore, the maximum distance (from well bore) that might be reached by acid effect could be predicted.

The total effect of acidizing parameters on wormhole length (x) can expressed as following:

$$
\mathrm{x}=\left(\mathrm{C} \frac{\Delta \mathrm{P} * \mathrm{Q}^{*} \mathrm{t}}{\mathrm{J} * \mathrm{~K}^{*} \cdot \mathrm{rwo}}\right)^{\mathrm{d}}
$$

Where:

$\mathrm{C}$ and $\mathrm{d}=$ empirical constants

$\Delta \mathrm{P}=$ Differential pressure, $\mathrm{Kg} / \mathrm{cm}^{2}$

$\mathrm{Q}=$ Acid injection rate, $\mathrm{cc} / \mathrm{min}$ $\mathrm{K}=$ Average Permeability, md $\mathrm{t}=$ Acid spending time (about $2 \mathrm{~min}$ ) or time of forming a wormhole experimentally to the end of core sample. $\mathbf{J}=$ Average rock density (for Yamama = about $2.71 \mathrm{gm} / \mathrm{cc}$ ) rwo $=$ average wormhole radius $(0.2 \mathrm{~cm})$ 


\section{Journal of Petroleum Research \& Studies}

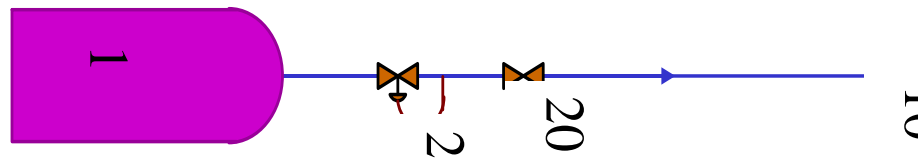

$\frac{1}{\infty a}$

o

尝

空

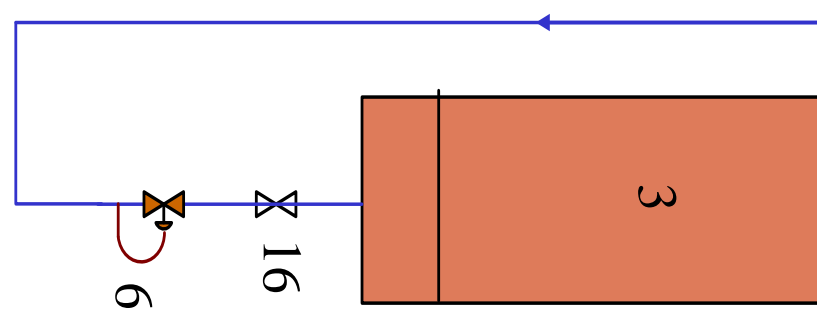

규유 $\Xi$. D 0 व

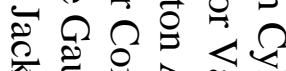

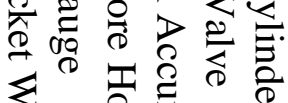

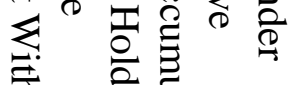
守

ڤ్

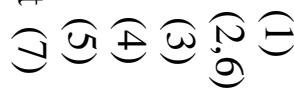

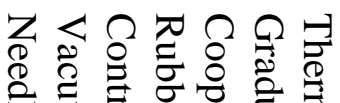

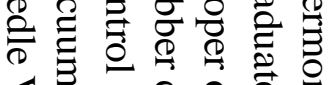
¿

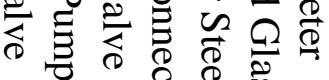

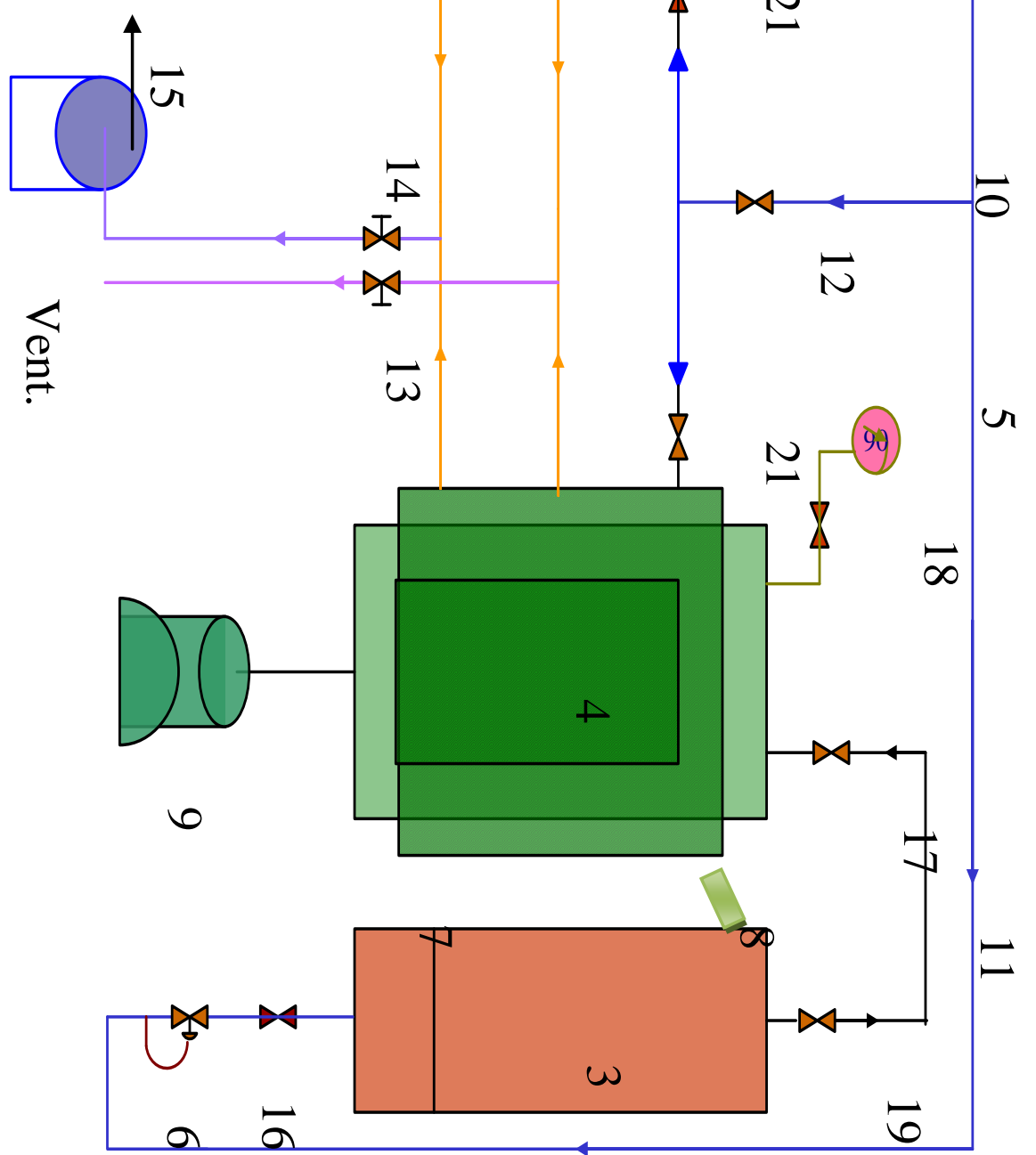

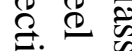
○. 0

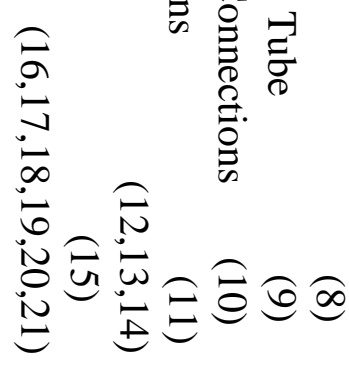


Substituting these parameters in equation 3, and after simplification to use for field applications, it becomes as the following:

$\mathrm{x}=\left(\begin{array}{ll}3.69 & \frac{\Delta \mathrm{P} * \mathrm{Q}}{\mathrm{K} \cdot \mathrm{N}}\end{array}\right)^{0.1}$

$\mathrm{N}=$ Number of perforations through it acid is injected

The length of wormhole causes as a result of an acidizing treatment depends on $(\mathrm{x})$ value. By application of experiments results using ( $\mathrm{x}$ ) value and true length of wormholes formed, it is found that length of wormhole related to (x) value by the following equation:
$\mathrm{L} \quad=$
2.17
$e^{x}$

Where: $\mathrm{L}=$ The length of worm hole formed by acid treatment, $\mathrm{cm}$
The following statistical properties were obtained after application of this equation on 8 core samples which completely penetrated by acid during matrix acidizing experiments:

1. Correlation coefficient $=0.958$

2. Standard deviation $=1.64$

3. Average absolute error percent $=6.395$

4. Average error percent $=0.115$

The application of this equation on field data of matrix acidizing gave a reasonable results according to the literatures of matrix acidizing. For example, when $\Delta \mathrm{P}=1500 \mathrm{psi}, \mathrm{Q}=500$ $1 / \mathrm{min}$, perforations interval $=10$ $\mathrm{m}$ and no. of perforations $=140$, the length of wormhole which calculated by this new equation equals to $2.6 \mathrm{f} \mathrm{t}$ (when $\mathrm{K}=15$ md.) and $1.72 \mathrm{f} \mathrm{t}$ (when $\mathrm{K}=50$ $\mathrm{md})$.

More applications are needed to generalize this equation for other conditions in all formations. 
The comparison between the

results obtained by this equation and that of other previous equations (22) proved that this equation is a good one for the conditions of the comparison.

\section{The main results of}

\section{experimental work}

The following main results
1. For the bottom-hole temperature of ( $\left.230^{\circ} \mathrm{f}\right)$ and for effective contact time of $10 \mathrm{hrs}$, the following ACI (Acid Corrosion Inhibitor) and NEA ( Non Emulsifying Agent ) should be used with Yamama oil and N-80 steel.

were obtained by the previous experimental work:

Table 1: Concentrations of acid corrosion inhibitor and non emulsifying agent for different HCL\%.

\begin{tabular}{|c||c||c||}
\hline HCL \% & ACI \% * & NEA\%** \\
\hline \hline 5 & $<0.25$ & 0.5 \\
\hline \hline 15 & 0.6 & 0.75 \\
\hline \hline 22 & 1.0 & 1.0 \\
\hline \hline 25 & 1.15 & 1.0 \\
\hline \hline 28 & 1.25 & - \\
\hline
\end{tabular}

* $\mathrm{ACI}-1$ is $\mathrm{A}-250$ (Halliburton product)

** NEA - 1 is the water solution of Iraqi detergent powder.

2. The above NEA\% represent to the optimum type and concentration which gave the best separation attained within 30 minutes.

3. According to the acid flow tests, stimulation of Yamama formation can be run as follow: 
Table 2: The optimum frequency (quantities and concentrations) of a matrix acidizing treatment for Yamama pay zones.

\begin{tabular}{|c|c|c|c|c|c|c|c|c|c|}
\hline \multirow{3}{*}{ HCL\% } & \multicolumn{9}{|c|}{ Required volume / Interval length } \\
\hline & \multicolumn{3}{|c|}{$10 \% \leq \emptyset<15 \%$} & \multicolumn{3}{|c|}{$15 \% \leq \emptyset<20 \%$} & \multicolumn{3}{|c|}{$\varnothing \geq 20 \%$} \\
\hline & P.V* & $\mathrm{Bbl} / \mathrm{f} \mathrm{t}$ & $\mathrm{m}^{3} / \mathrm{m}$ & P.V & $\mathrm{Bbl} / \mathrm{f} \mathrm{t}$ & $\mathrm{m}^{3} / \mathrm{m}$ & P.V & $\overline{\mathrm{Bbl} / \mathrm{ft}}$ & $\mathrm{m}^{3} / \mathrm{m}$ \\
\hline $\begin{array}{l}5 \% \\
\text { (pre- } \\
\text { flush) }\end{array}$ & 2.0 & 1.0 & 0.5 & 1.0 & 0.7 & 0.35 & 1 & 0.85 & 0.4 \\
\hline $15 \%$ & 3.0 & 3.0 & 1.5 & $3-4$ & 2.4 & 1.215 & 3.0 & 2.5 & 1.25 \\
\hline $\begin{array}{c}5 \% \\
\text { (after } \\
\text { flush) }\end{array}$ & 1.0 & 0.5 & 0.25 & 1.0 & 0.7 & 0.35 & - & - & - \\
\hline Total & 6.0 & 4.5 & 2.25 & $5-6$ & 3.8 & 1.95 & 4 & 3.35 & 1.65 \\
\hline
\end{tabular}

* P.V. $=$ Pore Volumes

\section{Design of a matrix acidizing}

\section{job (Paccaloni method)}

To design an acidizing job, the following variables need to be determined:

- Fracture gradient of the formation (which is needed to be stimulate).

- Maximum allowable wellhead injection pressure below fracturing.

- The maximum possible pumping rate.
- The type and concentration of acid and its additives.

Paccaloni method is one of the more useful design methods due to the following benefits:

- Degree of formation damage can be estimated with an injection test.

- Pumping parameters at the beginning of a matrix acidizing can be predicted.

- Can evaluate whether or not acid volumes used are 
too small, adequate, or excessive.

- Correct and quick decision can be taken at the wellsite, maximizing probability of success.

This method is based on the equation for steady state radial flow of incompressible fluid through a horizontal homogenous media ${ }^{(10)}$.

$\mathrm{P}_{\mathrm{wi}}-\mathrm{p}_{\mathrm{s}}=(204048 \mathrm{q} \mu / \mathrm{k} \mathrm{h}) \ln$ $\left(r_{b} / r_{w e}{ }^{-s}\right)$

Where:

$\mathrm{q}=$ injection rate, $\mathrm{bbl} / \mathrm{min}$

$\mathrm{k}=$ formation permeability, md

$\mu=$ injected fluid viscosity, $c p$

$\mathrm{p}_{\mathrm{s}}=$ formation static pressure, psi

$\mathrm{p}_{\mathrm{wi}}=$ bottom hole injection pressure, psi

$\mathrm{p}_{\mathrm{wi}}=\mathrm{Pi}+\mathrm{Ph}-\mathrm{Pfr}$ (7)

Pi, Ph, Pfr are wellhead injection pressure, hydrostatic head, friction losses respectively.
Using equations (5) and (6) the wellhead injection pressure can be expressed as a function of pumping rate and skin factor:

$$
\mathrm{Pi}=\left(\mathrm{P}_{\mathrm{s}^{-}} \mathrm{Ph}+\mathrm{Pfr}\right)+204048(\mathrm{q}
$$

$\mu / \mathrm{kh}) \ln \left(\mathrm{r}_{\mathrm{b}} / \mathrm{r}_{\mathrm{we}}{ }^{-\mathrm{s}}\right)$

Assuming $\mathrm{r}_{\mathrm{b}}=4 \mathrm{ft}$ (in most cases) in considered a good approach $(10,15,16)$ ensured by years of applying and validating of this method on more than 600 well reported matrix acidizing treatments ${ }^{(23)}$. The error causes from using steady state flow equation instead of transient flow equation is insignificant (for non - academic purposes) ${ }^{(23)}$

The flow type in stimulation jobs through tubing is almost turbulent flow ${ }^{(15,16)}$ and friction losses can be calculated by the following relation ${ }^{(10,23)}$ :

$$
\text { Pfr }=0.5623 \mathrm{~L} \mathrm{q}^{1.84} / \mathrm{d}_{\mathrm{i}}^{4.95}
$$

Where $\mathrm{L}=$ string length, $\mathrm{ft} ; \mathrm{q}=$ injection rate, (bpm). 


\section{Plotting Paccaloni graphs}

$\mathrm{B}_{\mathrm{y}}$ assuming injection rates

(q) and effective permeability (k) equation (7) can be used to determine wellhead injection pressure $(\mathrm{Pi})$ for many values of skin factor (s). Several curves of (q and Pi) can be plotted (one curve for each skin factor (s).

Effective permeability can be assumed depending on the past experience in the field.

A curve of maximum wellhead pressure to avoid fracturing can be plotted by calculating fracturing pressure and adding it to friction losses for each value of q. Fracturing gradient can be determined from instantaneous shut in pressure as a best source.

The resulted graph as in fig (7) can be used as a planning, executing guide and evaluating tool of matrix acidizing by the supervisor on the site. A p; ot of skin factor vs volume of injected fluid (field acid response curve) can be plotted while execution to get the best evaluation and quality control ${ }^{(22,23)}$.

Paccaloni charts was used in 4 previous acidizing jobs in Yamama formation (in which skin factor is determined before and after the job), good matching was found between skin factor detected from well test analysis an those detected from $(\mathrm{Pi}-\mathrm{q})$ chart ${ }^{(22)}$. 


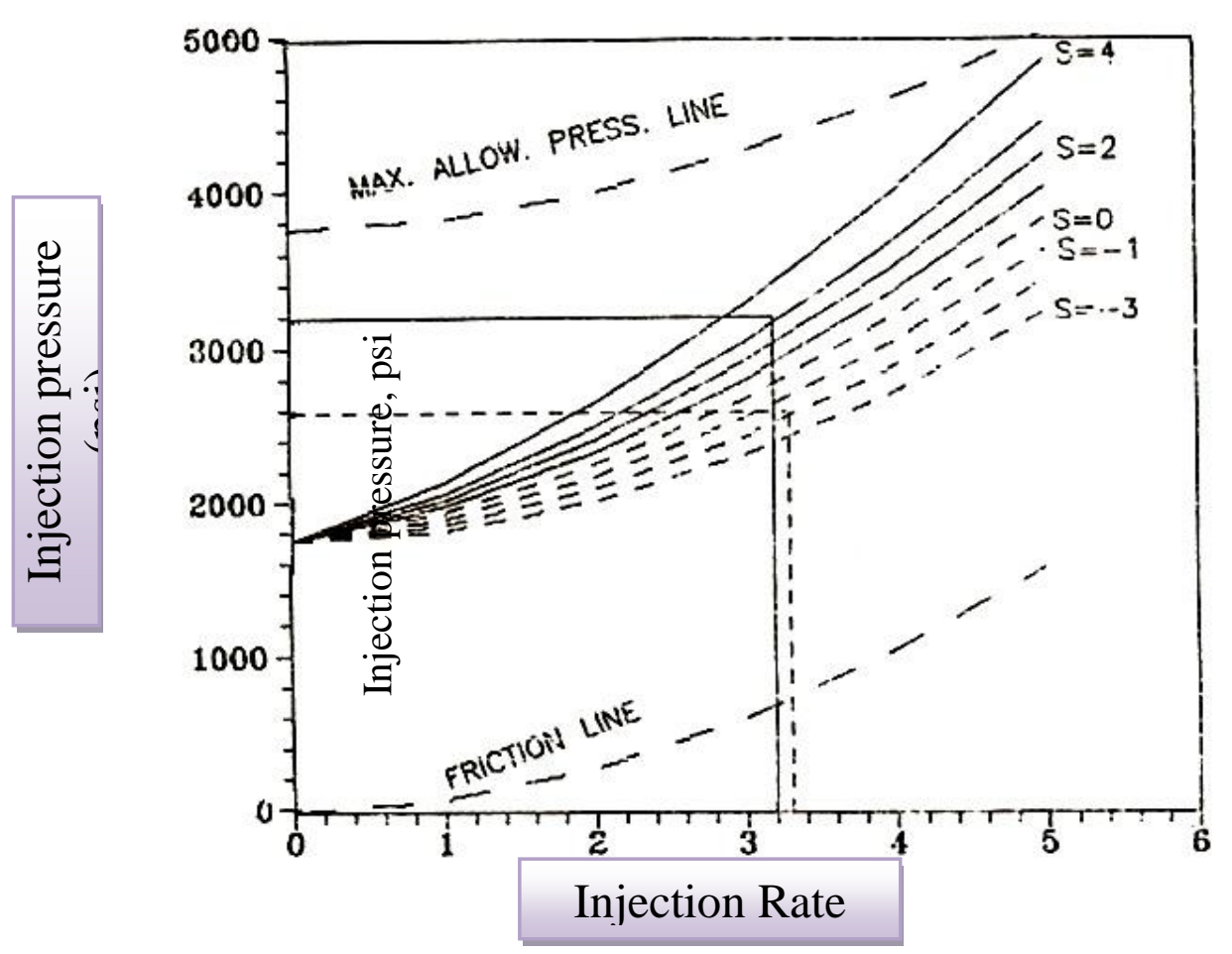

Fig (7) paccaloni Graph For Yamama Formation

\section{Conclusions}

1. The following techniques were suggested to design execute- and evaluate the matrix acidizing in yamama pay zones :

a. Using paccaloni planning - evaluation method .

b. Placing the acid solutions in front of the perforation interval .

c. It is recommended that an immediate opening of the well to flow is necessary after completion of acid injection .

d. Adequate cleaning period would be important after acidizing job.

2. A new empirical equation was developed which can predict the distance (from well bore) in the formation 
rocks, which the acid

effect is distance (from

well bore) in the formation

rocks, which the acid

effect is reaching to through matrix acidizing in yamama formation . this equation gave a good approach with experimental data and gave reasonable results (according to the literatures) when applicated on field data in yamama pay zone (see appendix - a and other details in reference $\left.{ }^{(22}\right)$. 


\section{References:}

1. Lake, L.W. and Clegg I. D., 2007, "Petroleum Engineering Handbook, volume IV: Production Operations Engineering" Society of Petroleum Engineers, Richardson.

2. Carl, M.T., 2004, "Method for enhancing well productivity" United States of Patent Application.

3. Van Everdengen, A.F.,1953, "The skin effect and its influence on productive capacity of a well" Trans. AIME 182, P-171.

4. Mathews, C.S. and Russell, D.G., 1967, "Pressure build-up and flow tests in wells" SPE monograph vol.1, Henry L. Doherty series, NY.

5. Lee, J., 1982, "Well testing" SPE text book series, vol.1 Dallas.

6. Roberts, L. and Allen, A., 1989, "Production operations" vol.2, Oil and Gas Consultants International, Tulsa.

7. Putnam, S.W., 1933, "Development of acid treatments of oil wells involves careful study of problems of each" OGJ, P-8.

8. Ely, J.W.,1985, "Stimulation treating handbook - an engineering guide to quality control" Penn well books, USA.

9. McLeod, H.O. and Coulter, A.W., 1969, "The stimulation treatment pressures record an over-look at formation evaluation tool" JPT, P-951-960.

10.Paccaloni, G., 1979, “A new method proves value of stimulation planning" OGT.

11.Schlemberger, Dowell , 1994, " Recent developments in matrix acidizing" Seminar, Baghdad.

12.Williams, B.B., Gidley, J.L., Guin, J.A. and Schechter, R.S., 1970, "Characterization of liquid-solid reaction" Ind. Eng. Chem. Fund., vol.9. 
13.Nierode, D.E. and Williams B.B. ,1971,"Characteristics of acid reaction in limestone formation" SPEJ, P406 - 418.

14.Economides, M.J., Frick, T.P. and Nittman, J., 1994, "Enhanced visualization of acid carbonate rock interaction" (research note), JPT.

15.Morrica, G. , 1981,"Stimulation studies of Halfaya field" Agip, Milan, Italy.

16.Agip , 1986, "West Qurna stimulation studies" Agip, SPAproduction engineering, Italy.

17.Ghetto G.D. and Galoppini, M.,1986, "Stimulation of multilayered reservoir. A new approach to optimize the treatment volumes" Agip, Italy.

18.Abdel-Amer, M.R., 1987, "Stimulation of oil well of Mishrif reservoir" M. Sc thesis, Baghdad university.

19.Al-Taii, S.H. , 1988,"Laboratory investigation concerning the stimulation of some Iraqi oil wells" M. Sc thesis, Baghdad university.

20.SOC "Well testing, stimulation, evaluation, technical reports, lab. Studies, core analysis, geological studies and well final reports" Basra, Iraq.

21.Mohammed Dhahbi, G.A. and Zainal, E.F., 1993, "Regional geological study for Yamama formation in south of Iraq" Pet. Exp. Co., Baghdad.

22.Alwan, Kareem A.: , 1997, "Stimulation of Yamama pay zones" M. Sc thesis, Baghdad university.

23.Paccaloni G. and Tambini M., 1993, "Advances in matrix stimulation technology" JPT, p 256. 